DOI: $10.17805 / z p u .2015 .4 .12$

\title{
Становление и раннее развитие сербского летописания*
}

\author{
C. В. АЛЕКСЕЕВ \\ (МОСКОВСКИЙ ГУМАНИТАРНЫЙ УНИВЕРСИТЕТ)
}

Статья посвящена становлению и раннему развитию летописного жанра в Сербии XIV-XV вB. Преобладание архаического восприятия истории и исторического времени обусловило в Сербии длительное господство историко-генеалогических форм описания прошлого.

В 70-х годах XIV в. происходит прямой перенос архаической формы родослова в писаную литературу через создание «Родослова бана Твртко». Однако одновременно появляется и произведение хроникального типа - так называемая «Старшая сербская летопись». В ней еще мало точных хронологических привязок, повествование построено как цепь кратких жизнеописаний правителей. Однако точные датировки все-таки появляются, и изложение строже организовано по хронологическому принципу, чем в житийном цикле или родослове. Летописная форма возникала под воздействием как со стороны Византии (через Болгарию), так и с запада, из латинского Приморья, что демонстрирует краткий летописец конца XIV в. из Дубровника. Имеется ряд кратких летописчиков XV в. Наиболее ранние из них (Хаци-Йорданова летопись, Данилчев летописчик) являются свидетельством быстрого восприятия собственно летописной формы сербскими авторами. Вместе с тем эти памятники весьма лаконичны и содержательно небогаты. Относительно развернутым сербское летописание становится с появлением в середине XV в. первой из так называемых «Младших летописей». Она уже включала воспринятые у византийских хронистов сведения по библейской и всемирной истории.

С появлением этого первого сербского летописного свода начинается уже стабильное развитие летописной традиции. Характерно, что произошло это только с падением старой сербской государственности.

Ключевые слова: Средние века; источники; южные славяне; Сербия; летописи; родословы

\section{ВВЕАЕНИЕ}

$\mathrm{O}$ дной из заметных особенностей сербской исторической литературы Средневековья было крайне позднее развитие летописного жанра. Первые сербские исторические сочинения - «хроники» без хронологии, разбитые по правлениям монархов ( «Аетопись попа Ауклянина», а позднее и так называемая «Старшая летопись»), или королевские жития. Одной из причин этого являлся архаизм сербской средневековой культуры, в том числе восприятие истории через призму изначально устной генеалогической традиции (см.: Алексеев, 2014). В настоящей статье рассматриваются первые шаги становления летописания в Сербии XIV-XV вв., вырастание его из традиции литературного родослова.

\section{СЕРБСКИЙ РОАОСАОВ И СТАРШАЯ АЕТОПИСЬ}

Зарождение новых форм историописания в Сербии относится к последним десятилетиям XIV в., когда были созданы, с одной стороны, так называемый «Родослов бана Твртко» (далее - Родослов) (Стојановић, 1927: 2-39), а с другой - «Старшая сербская летопись» (там же: 62-104). На самом деле оба эти памятника, связанные временем возникновения и содержанием, являются лишь предтечами летописного жанра,

* Подготовлено при поддержке РГНФ (проект «Памятники сербской средневековой историографии XII-XVII вв.: перевод и исследование», грант № 13-01-00118a).

The research was conducted with support from the Russian Foundation for the Humanities (Project title: "Monuments of the Serbian Medieval Historiography of the 12th-17th Centuries: Translation and Investigation", grant No. 13-01-00118a). 
в равной степени показывая прочную связь сербской средневековой историографии с устной генеалогической традицией.

С. Новакович и $\Lambda$. Стоянович, первыми занявшиеся детальным исследованием сербских родословов, полагали, что древнейшая форма родослова могла быть создана в первой половине XV в. Константином Философом-Костенецким. Соответственно, в числе источников родослова оказывались «Старшая летопись» и ряд других письменных памятников второй половины XIV - начала XV в., не говоря о более ранних. Однако А. Радойчич (Радојчић, 1948), рассматривая содержание и структуру первоначального родослова, убедительно связал появление его протографа с коронацией боснийского бана Твртко королем Сербии и Боснии в 1377 г. Аействительно, Родослов обосновывает принадлежность Твртка к роду Неманичей и его права на престол, в то же время называя его еще лишь баном, т. е. только подкрепляя будущее принятие королевского титула. В Сербии Родослов расширялся в конце XIV - первой половине XV в., что отразилось в его списках. Расширение это происходило при дворе сербских деспотов Хребеляновичей - Бранковичей, родоначальник которых князь Аазарь являлся союзником Твртка. В частности, при дворе Стефана Аазаревича с Родословом работал Константин Костенецкий, создавший позже для жития деспота собственную его оригинальную сокращенную версию.

Соответственно, иначе по сравнению с видением впервые детально рассмотревшего эту проблему $\Lambda$. Стояновича решается вопрос и об источниках Родослова. Основная часть информации Родослова о генеалогии и правлении Неманичей - устного происхождения. На это указывают и грубые ошибки, относящиеся как к полулегендарным временам (превращение отца и одного из дядьев Немани в его братьев), так и к временам, уже описанным в «Житиях королей и архиепископов» (разделение короля Уроша I на двух персонажей, якобы отца и сына). Последнее свидетельствует также против работы автора Родослова в собственно Сербии и против его непосредственного знакомства не только с житиями, но и с иконографическими родословами. История о двух крещениях Немани, которую Стоянович считал восходящей к «Житиям св. Симеона» Стефана Первовенчанного и Савы, в Родослове излагается совершенно иначе, чем там, - Неманя крестится уже в зрелом возрасте, причем именно о двух крещениях говорится только в авторской Паисиевой редакции. Вероятные заимствования из летописей имеются лишь в двух из четырех редакций старейшего Родослова, Паисиевой и Карловацкой, причем разные в той и другой. Только в одном Карловацком списке использованы «Житие Стефана Аечанского» Григория Цамблака и «Житие Стефана Мазаревича» Константина Костенецкого.

При создании фантастической легенды о происхождении Немани от римского императора Аициния автор Родослова использовал письменные источники, как минимум Пролог. Славянский «Паралипоменон Зонары» использовался в редакции, близкой сербской переработке при дворе Стефана Аазаревича (1408 г.). Однако сама по себе легенда не была всецело изобретением автора - византийская генеалогия для Неманичей родилась в окружении жены, затем вдовы Аушана Елены Асень-Комнин уже в 1350-х годах и отразилась в плохо сохранившейся «лозе Неманичей - АсенейКомнинов» со стены церкви Богородицы в Матейче. Автор Родослова лишь поместил ее в рамки фантасмагорической картины истории, в которой Неманя оказывается правнуком Аициния. Таким образом, автор был совершенно неспособен даже приблизительно соотнести хронологию Зонары с сербской историей, также он был незнаком с подробностями «официальной» сербской версии. Это еще одно подтверждение его 
работы вне Сербии и вообще в удалении от центров не только византийского, но и в целом внешнего культурного влияния. Находившаяся в религиозной полуизоляции Босния является логичным вариантом. Хотя необходимо отметить, что автор был православным и, скорее всего, выходцем из собственно Сербии или Приморья, - может быть, не в первом поколении. Не исключено, что непосредственное знакомство с хроникой Зонары относится уже к позднейшим переработкам Родослова в первой половине XV в., с чем связаны серьезные расхождения списков в его начальной части.

Памятник, определяемый как «Старшая сербская летопись», был создан в 70-х гоAax XIV в. (скорее всего, в 1372-1373 гг.), примерно в тот же смутный период сербской истории, что и первоначальный Родослов. Исходная форма «Старшей летописи» отразилась в Копоринском и Врхобрезницком ее списках, доведенных до битвы на Марице и смерти царя Уроша (конец 1371 г.). В дальнейшем «Аетопись» была продолжена до 1391 г. - эта редакция отразилась в Печском, Студеницком и Цетиньском ее списках.

Первоначальный автор «Аетописи» неизвестен. Он принадлежал к политическим сторонникам эпирских Неманичей (в отличие от создателя Родослова, приверженца Твртка и Аазаря) и писал, по всей видимости, в южных областях Сербского царства. Продолжатель его трудился при дворе Стефана Аазаревича и, соответственно, являлся сторонником и апологетом Хребеляновичей. Создателя текста, отразившегося в Печском списке, иногда идентифицируют под именем Аавид (хотя это может быть имя переписчика или даже владельца рукописи).

Образцом для «Аетописи» послужила появившаяся в Сербии во второй половине $\mathrm{XIV}$ в. «Хроника» Георгия Амартола в славянском переводе. Поскольку «Хроника» разбита по правлениям царей и императоров и в сербском изводе сопровождается их хронологическим перечнем - «Сказанием вкратце», то и « гие черты привычного сербам родослова. Точные даты в ней появляются лишь с 1317 г. и встроены в главы, посвященные правлениям, как и в некоторых поздних родословах. Строго говоря, это именно «хроника» с явными элементами генеалогического предания, наподобие « $е$ тописи попа Ауклянина», а не летопись в собственном смысле слова. Источниками « Аетописи» послужили как устные предания, так и жития, а также хронологические записи, в основном поминальные.

Иетопись известна в пяти списках. Старейший Копоринский, отражающий первоначальную редакцию 1370-х годах, создан в 1453 г. в Копоринье диаконом Аамианом по заказу архиепископа Зеты Иосифа. Список хранился в библиотеке монастыря Крушедол. Аругой список той же редакции - Врхобрезницкий 1650 г. - содержится в хронографическом сборнике с Родословом и младшей летописью. Он происходит из монастыря Врхобрезницы в Плевле (Черногория) и выполнен иноком Гавриилом в 1650 г. Начало Аетописи в нем сильно сокращено и к тому же «исправлено» по Родослову - в частности, введено «удвоение» Уроша I.

Наиболее ранний список редакции времен Стефана Аазаревича - Печский начала XVI в., находящийся в Российской национальной библиотеке. Он содержит большую лакуну (нет листа) и в целом уже в XIX в., когда А. Ф. Гильфердинг привез его из Печа, находился в плохом состоянии. Собственно, это фрагмент несохранившегося сборника. Печская редакция «Иетописи» включает отсутствующий в других списках каталог «О патриархах земли Сербской», составленный между 1382-1388 гг. при патриархе Спиридоне.

Студеницкий список, хранившийся в Народной библиотеке Сербии, является частью сборника, включающего также «Младшую летопись» Первого вида. Список дати- 
руется в пределах XVI в. В 1760 г. он находился в Студеницком монастыре, где копия с него была включена в сборник, содержащий также «Житие св. Симеона» и «Жития архиепископов». Та же редакция « $\Lambda$ етописи» отражена в Цетиньском списке конца XVI в., находившемся в 1830 г. в собственности митрополита Черногории Петра Негоша и попавшем позже в библиотеку Одесского университета. Студеницкий и Цетиньский списки восходят к общему протографу, входившему в сборник с «Младшей летописью» Первого вида в изводе 1490 г. При этом в Цетиньском списке «Старшая летопись» продолжена до 1516 г., а «Младшая летопись» Первого вида - до 1574 г.

Печский и Студеницко-Цетиньский изводы имеют ряд существенных отличий, и их соотношение между собой не до конца понятно. В Печском списке дается развернутая похвала князю Аазарю, тогда как Студеницкий и Цетиньский списки содержат более пространное описание Косовской битвы. Вторичность той или другой версии неочевидна. Возможно, и в Печском, и в Студеницко-Цетиньском изводе по-разному, но еще в окружении Стефана Аазаревича (до 1427 г.), дополнялся первоначальный вид продолженной « ко-Цетиньском изводе «Иетопись» к тому же получила новое, более длинное название и была заметно отредактирована в начальных главах. В то же время и Печский список дает отдельные дополнения в начальные главы, имеющиеся только в нем, иногда оказываясь дальше от Копоринского, чем Студеницкий и Цетиньский. Создание редакции «Аавида» иногда датируют 1402-1405 гг.

\section{КРАТКИЕ АЕТОПИСЧИКИ ХIV-XV ВВ.}

Говоря о сербской историографии конца XIV в. и об источниках внешнего влияния на становление летописного жанра, следует упомянуть и еще один памятник. На последнем листе рукописного кириллического лекционария из Аоминиканского монастыря в Аубровнике сохранился маленький летописчик, включенный $\Lambda$. Стояновичем в его издание сербских летописей (Стојановић, 1927: 115). Основания к этому есть прежде всего явный интерес составителя к сербской истории.

Иетописчик написан на смеси церковнославянского и живого языка, со своеобразной системой записи дат (в кириллических числах для обозначения 1000 используется буква $\psi ;$ кириллические цифры дублированы арабскими). Источником летописчика стали известные по позднейшим италоязычным спискам и созданные в XIV-XV вв. дубровницкие анналы, краткой выборкой нескольких известий из которых он и является. Однако анналы использованы в их старой, несохранившейся и более достоверной (в описании и датировке основания города; в хронологии появления городских святынь) форме. Запись о битве на Марице ближе текстуально к раннему изводу «Старшей сербской летописи», чем к анналам. Все это позволяет отнести создание летописчика ко времени, примерно соответствующему последней внесенной в него дате (1371 г., в тексте ошибочно 1361). Аата, очевидно, изменена при переписывании, когда обнаружился хронологический «сбой» - запись о битве на Марице в протографе оказалась поставлена раньше, чем совпадающая по дате с анналами запись под 1370 г. о войне Аубровника с жупаном Николой.

C XV в. летописная форма распространяется все шире. Хаци-Йорданова летопись (там же: $112-114,125-150$ ) сохранилась в одной рукописи XVI-XVII вв. с так называемым Хаци-Йордановым родословом. Аетописная часть сборника состоит из двух разделов. Первый представляет собой список «Сказания вкратце» из сербской «Хроники Амартола» - памятника, послужившего образцом для сербских летописцев 
и источником их сведений о древней истории. Второй раздел - сербская летопись, доведенная до 1433 г. Та же летопись, но доведенная лишь до 1405 г., с более точными датами и, видимо, более ранними чтениями, была издана $\Lambda$. Стояновичем по единственному листу, обнаруженному им в Народной библиотеке Сербии. Вероятно, летопись за 1355-1405 гг., имевшаяся там, являлась источником или, точнее, первоначальной формой Хаци-Йордановой. Была ли она уже тогда привязана к «Сказанию вкратце», неизвестно. В любом случае, это древнейший или один из древнейших собственно летописных памятников Сербии.

Иетописчик, доведенный до 1408 г., был включен в так называемый «Аанилчев Типик». Судя по содержанию, составлен он вместе с рукописью Типика в 1416 г. Насколько можно судить, это один из древнейших (наряду с протографом Хаци-Йордановой летописи) в полном смысле слова летописный памятник в сербской литературе. В основном он состоит из поминальных записей (там же: 111).

Помимо Хаци-Йордановой летописи и Аанилчева летописчика, $\Lambda$. Стояновичем было выявлено среди летописных заметок еще четыре кратких летописчика, которые могут быть отнесены к XV в. (там же: 118-120) Они (или иные памятники этого типа) могли служить как источниками пространных летописей, так и выборками из них.

\section{«МААДШАЯ АЕТОПИСЬ» ПЕРВОГО ВИАА}

«Младшая летопись» Первого вида (первая группа младших летописей, по $\Lambda$. Стояновичу) (там же: 121-153, 205-257) начала складываться в середине XV в. Первоначальная ее форма - летописный свод, созданный в последние годы существования Смедеревской деспотовины. Создание этого летописного памятника $\Lambda$. Стоянович отнес к 1458-1459 гг., однако на деле относительно сходный текст всех списков следует не далее 1453 г. Свод (условно Свод 1453 г.), вероятно, дополнялся записями до 1461 г., к которому относилась его последняя статья. Он включал «Сказание вкратце» (в редактированном и сокращенном, но кое-где и дополненном виде) и описание событий сербской истории за 100 лет, начиная со смерти царя Стефана Аушана. Задачей создателей Свода 1453 г., вероятно, было дополнить «Старшую летопись» записями о трагических событиях новейшей истории. Источником послужил стихийно складывавшийся обширный фонд летописных заметок и малых летописчиков. Из последних явно использовалась и служила образцом Хаци-Йорданова летопись, в которой впервые событиям сербской истории предпослано «Сказание вкратце». По мнению $\Lambda$. Стояновича, важным источником для сербских летописцев служило «Житие Стефана Аазаревича» Константина Костенецкого, содержавшее датировки ряда событий. Однако данное влияние представляется преувеличенным.

Свод 1453 г. (со статьями до 1461 г.) сохранился в единственном списке второй половины XVI в., хранящемся в Народной библиотеке Кирилла и Мефодия, - Софийский 1-й (далее - C1), по $\Lambda$. Стояновичу. Известна поздняя, XVIII в., болгарская копия, по которой в изданиях восполнялась утрата листа в рукописи. Аетопись продолжена в C1 тремя записями за 1536-1567 гг. После создания списка были приписаны еще несколько статей, до 1622 г., с еще одной записью за 1695 г.

По мнению $\Lambda$. Стояновича, в 1484 г. или вскоре после первоначальный свод был дополнен известиями о прошедшем времени. Однако, судя по сопоставлению списков этой редакции, их схождение продолжается как минимум до 1485 или 1486, а отчасти до самого 1490 г., которым завершаются (по-разному) два списка из пяти. В этом своде (условно - Своде 1490 г.) существенному расширению и редактированию подверг- 
лись и известия за 1356-1453 гг. В Свод 1490 г. была включена также новая версия «Сказания вкратце», сверенная с оригиналом и существенно расширенная за счет известий Амартола и других переводных хроник (Зонары, Манассии), а также сведений по истории поздней Византии. В результате была закрыта лакуна, образовывавшаяся в Своде 1453 г. между византийскими событиями IX в. и смертью Аушана, с которой начиналось повествование о новейшей истории Сербии. В дальнейшем в двух списках Свод 1490 г. самостоятельно продолжался. В то же время продолжения имеют и явные совпадения, свидетельствующие о том, что наиболее ранние вышли из одного круга, а в позднейшем (Цетиньский список) они использовались.

Известно пять списков Свода 1490 г. Киевский список (далее - K), в XIX в. находившийся в Почаевской лавре, хранится ныне в Библиотеке Национальной академии наук Украины. Он создан в Молдавии между 1554 и 1562 гг. и включает также молдавскую летопись начала XVI в. Рукопись впервые издана в 1891 г. Ее язык характеризуется смешением болгарских, сербских и русских элементов. Здесь еще раз расширено «Сказание вкратце» прежде всего за счет хронологии ветхозаветных праотцов и подробных рассказов о Вселенских соборах.

Студеницкий список (далее - $\mathrm{C}_{\mathrm{f}}$ ) содержится в охарактеризованном ранее сборнике со «Старшей летописью», происходящем из Студеницкого монастыря. Список датируется XVI в. Имеется добавочная статья за 1641 г.

Сарандапорский список (далее - Сар) происходит из Сарандапорского монастыря в Македонии; рукопись, найденная в Национальном музее Боснии и Герцеговины (ранее Сараевский национальный музей) и изданная в 1894 г., включает также литургические тексты. Список имеет продолжение до 1510 г. Кроме того, «Сказание вкратце» дополнено здесь подробными рассказами о крещении болгар и Руси.

Цетиньский список (далее - Ц) содержится в охарактеризованном ранее сборнике со «Старшей летописью» и восходит к общему оригиналу со Ст, включавшему «Старшую летопись» в особой редакции и Свод 1490 г. Продолжение доведено здесь до 1574 г. В ряде мест Ц сходится с C1 против всех остальных списков, что наводит на мысль о правке по Своду 1453-1461 гг. или какой-то близкой летописи (возможно, с продолжением типа Сар).

Никольский список (далее - Н) (Новаковић, 1955) очень близок Ц и отчасти Сар, а в «Сказании вкратце» почти тождествен Ц. Он входит в состав сборника, содержащего тексты исторического и религиозного содержания, из монастыря Николец в Белом Поле, и был впервые опубликован в 1931 г. Список не имеет начала и обрывается на 1496 г.; датируется он XVI в. Начиная с известия 1474 г. он заметно расходится с остальными текстуально, хотя и сохраняет структурную близость. На этом отрезке содержится ряд оригинальных известий и большой вставной сюжет о царе Мехмеде. Статьи 1488-1495 гг. почти совпадают с Ц, но только с Ц. Близость Н к Ц наводит на мысль, что протограф Н, будучи родствен Ц по происхождению, мог быть его источником или одним из дополнительных источников в завершающей части, но отсутствие статей за XVI в. не позволяет утверждать это с уверенностью. Текст типа Н использовался при создании Бранковичевой летописи в начале XVII в., которая в статьях за первую половину XVI в. во многом совпадает с Ц.

\section{ЗАКАЮЧЕНИЕ}

Появление «Младшей летописи» знаменует собой окончательно сложение летописного жанра. Вместе с тем его развитие в сербских землях и позднее сохраняло ряд 
особенностей. Это прежде всего сильное влияние родословной традиции, особенно в повествованиях о Неманичах. Кроме того, можно отметить подчас весьма бросающееся в глаза невнимание сербских летописцев к заимствованной ими хронологии библейской и античной истории - датировки событий, весьма варьирующиеся в их произведениях, явно имели для авторов меньшее значение, чем перечисление поколений. Аетописание в собственном смысле слова, видимо, рассматривалось как наилучшая форма описания событий современных, когда за неимением своих правителей описание исторического времени по их поколениям оказалось невозможным. Записи сербских летописцев крайне лапидарны, почти не содержат развернутых сюжетов. При всем том сербское летописание является ценнейшим источником по истории Сербии времен османского завоевания и владычества.

\section{СПИСОК АИТЕРАТУРЫ}

Алексеев, С. В. (2014) Сербская историческая агиография: между хроникой и житием // Знание. Понимание. Умение. № 3. С. 148-156.

Новаковић, Р. (1955) Никољски летопис // Зборник Филозофског факултета у Београду. Књ. 3. С. 160-169. (На сербск. яз.).

Радојчић, Ђ. С. (1948) Аоба постанка и развој старих српских родослова // Историјски гласник. Т. 2. С. 21-36. (На сербск. яз.).

Стојановић, Љ. (1927) Стари српски родослови и летописи. Београд ; Сремски Карловци : Српска Краљевска академија. 382 с. (На сербск. яз.).

Аата поступления: 16.09 .2015 2.

THE ORIGIN AND EARLY DEVELOPMENT OF THE SERBIAN ANNALS

S. V. ALEKSEEV

(MOSCOW UNIVERSITY FOR THE HUMANITIES)

The article is devoted to the origin and early development of the annalistic genre in 14 th- 15 th century Serbia. The predominance of archaic perception of history and historical time gave prominence to historical genealogical forms of description of the past in Serbia.

In the 1370s, the archaic form of genealogy was transferred to written literature through "The Genealogy of Ban Tvrtko". The so-called "Elder Serbian Chronicle" appeared at the same time. It still had few accurate chronological ties-in, and the narrative is constructed as a series of short biographies of the rulers. However, precise dating is already there, and the chronicle features a more strict chronology than a hagiographic text or genealogy. Annalistic form originated under the influence of both Byzantium (via Bulgaria) and the Latin Adriatic, as seen in the concise Dubrovnik annals (late 14th century). A number of short annals have survived from the 15th century. The earliest of them (Hatsi-Yordanov annals, Danilchev annals) reveal how rapidly annals as a genre were appropriated by Serbian authors. However, these works are very succinct and poor in content, with Serbian annals getting more detailed in the mid-15th century when the first of the so-called "junior chronicles" was written. It already included information on biblical and world history borrowed from Byzantine chroniclers.

With the advent of this first Serbian annalistic code, stable development of the annalistic tradition began. Characteristically, it coincided with the fall of the old Serbian statehood.

Keywords: Middle Ages; sources; South Slavs; Serbia; genealogies; annals

\section{REFERENCES}

Alekseev, S. V. (2014) Serbskaia istoricheskaia agiografia: mezhdu hronikoi i zhitiem [Serbian historical hagiography: Between the chronicle and vita]. Znanie. Ponimanie. Umenie, no. 3, pp. 148-156. (In Russ.). 
Novakovich, R. (1955) Nikoljski letopis [Nikoljski annals]. Zbornik Filozofskog fakulteta u Beogradu, bk. 3, pp. 160-169. (In Serb.).

Radojchich, D. S. (1948) Doba postanka i razvoj starib srpskib rodoslova [The time of origin and development of Old Serbian genealogies]. Istorijski glasnik, vol. 2, pp. 21-36. (In Serb.).

Stojanovich, L. (1927) Stari srpski rodoslovi $i$ letopisi [Old Serbian genealogies and annals]. Beograd ; Sremski Karlovci, Srpska Kraljevska akademija. 382 p. (In Serb.).

Submission date: 16.09 .2015 .

Алексеев Сергей Викторович - доктор исторических наук, профессор, заведующий кафедрой истории Московского гуманитарного университета, председатель правления Историкопросветительского общества «Радетель». Адрес: 111395, Россия, г. Москва, ул. Юности, А. 5, корп. 3. Тел.: +7 (499) 374-55-81. Эл. адрес: ipo1972@mail.ru

Alekseev Sergey Viktorovich, Doctor of History, Professor and Chair, Department of History, Moscow University for the Humanities; Chairman, Radetel Historic-Educational Society. Postal address: Bldg. 3, 5 Yunosti St., 111395 Moscow, Russian Federation. Tel.: +7 (499) 374-55-81. E-mail: ipo1972@mail.ru 